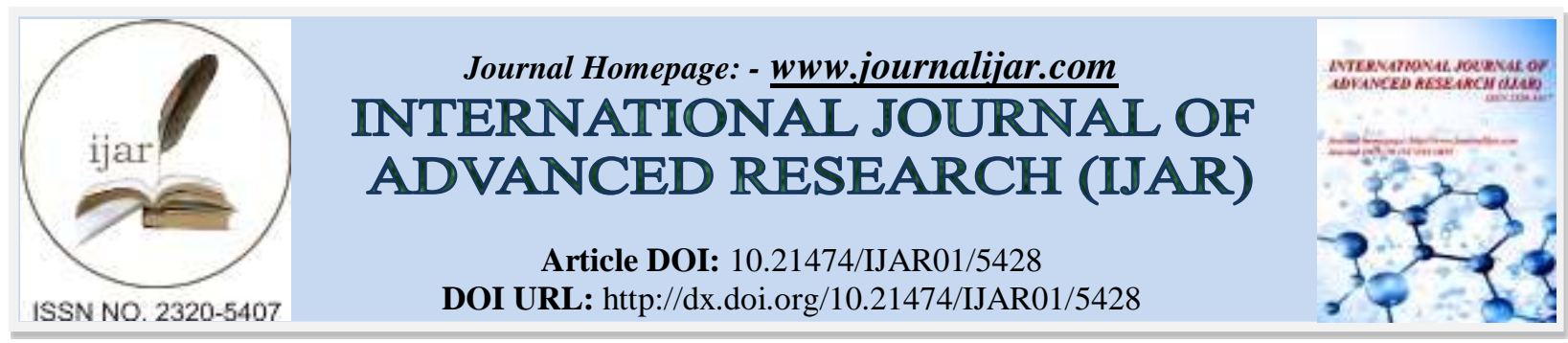

RESEARCH ARTICLE

\title{
LANDSCAPE DESIGN AS A TOOL TO ENHANCE RESIDENTIAL SPACES AND PLACES IN SAUDI ARABIAN CITY URBAN FABRIC.
}

Talal Hammadi.

Associate professor of Landscape Architecture, (Ph.D., MLA), Faculty of Islamic Architecture, College of Engineering and Islamic Architecture, Umm Al-Qura University, Makkah Al Mukarramah, Saudi Arabia.

\section{Manuscript Info}

Manuscript History

Received: 14 July 2017

Final Accepted: 16 August 2017

Published: September 2017

Key words:-

urban residential area, urban areas,

landscape design, living environment.

\begin{abstract}
The environment of residential area has a closed relationship with peoples' pattern of the daily life. It is not only an important place of social activities, but also an important constituent in urban setting. Along with the development of society and economy, the residential landscape is also changing. However, in the course of development, many problems have appeared. These issues have had negative effect on the quality of landscape and seriously stuck the development of residential landscape design for the future. In this paper, urban residential landscape was selected as the research focus, to suggest some operational solutions for the current problems that associated with design of urban residential space and places. The ultimate aims of this paper are to get some motivation about how landscape design might enhance and develop urban residential spaces and places, and also as a mean to avoid the redundant mistakes in future. Finally, some landscape design principal approaches had come up for a melioration of urban residential landscape.
\end{abstract}

Copy Right, IJAR, 2017,. All rights reserved.

"Developing sustainable neighborhoods should be guided by the principle of universal design. Universal design is the design of an environment so that it can be accessed, understood and used to the greatest extent possible by all people regardless of their age, size, ability or disability. ${ }^{11}$

\section{Introduction:-}

Inhabitation is a basic survival need for human. It is the most important living constituent and behavior content of human ${ }^{2}$ It was obvious, that in the growth of the human improvement the residential regions have been continuously a base of human constant development. Consequently, the environment of residential area has familiarly closed relationship with human beings. The setting urban residential spaces and places also show a vital role in urban landscape pattern. The current living environment is no longer the easy living space, but one of the essential places for societies to enjoy and communicate. With corresponding to the four essential elements which are worship, work,

${ }^{1}$ Guidelines for Planning Authorities on: Sustainable Residential Development in Urban Areas (Cities, Towns \& Villages), (2009), SUN ALLIANCE HOUSE, MOLESWORTH STREET, DUBLIN 2, Government of Ireland.

${ }^{2}$ JiaYan, 2002, _Talk About the Needs of People and the Design of External Space in Residential Areas', Journal of Liaoning Institute of Technology, no.2 
live and entertainment, residential area becomes the bay with natural and tranquil environment when people come home after a busy work ${ }^{3}$. A comfort and a healthy satisfying residential environment is an innate demand for urban resident. As the people's living standard is improving, more and more residents have gradually converted from the simple pursuit of comfortable residential areas to the higher quality requirements of outdoor open spaces. It is an essential to have a relaxed alive atmosphere in the leisure time. Urban societies spend half and even two-thirds of the whole day in residential areas. Therefore, the quality of environment directly affects people's physical, mental and spiritual life ${ }^{4}$, such a development undoubtedly brings a higher demand for a more fabulous environmental landscaped designed and planning schemes. In short, we might pay more attention to residential urban landscape outdoor areas.

In Saudi Arabia, the spate of modernization has led to the replacement of traditional urban structure and form by "Western models" of urban form and design. This has resulted in problematic urban development, as Western models are adopted without recourse to the underlying principles and sociocultural background of the traditional form. In the drive towards sustainable cities through design, the challenge is to develop a framework that will adapt traditional urban form to changes in the face of Western models of urban form. ${ }^{5}$ Numerous apartment buildings have been built and the residential areas have attained a new look, compared to the development speed of residential community, the research on residential environment and landscape design were lagging behind. The subject of landscape design in Saudi Arabia did not have an integrated system. Nowadays, the majority of landscape designs are limited to the overall planning while ignoring the features shape of the landscape design. Moreover, in practice, people complain quite often on many problems such as the scarcity of outdoor urban recreational places and spaces, environmental pollution and deterioration of local vernacular environment. Some environmental constructions of residential areas were deviated from the principle of "landscape architecture", and blindly pursuing alien and inadequately designing outdoor open areas. Therefore, this paper will explore how to improve the comprehensive quality of urban residential places and spaces, and at the same time, to provide some references for the abovementioned problems through several practical landscape design methods and principles.

\section{Urban Growth Trends in Saudi Arabia:-}

Saudi Arabia is one of the most rapidly urbanizing countries in the world; its free market economy has undergone remarkable changes in a relatively short period of time. It has evolved from a basic agricultural society into a regional and global economic power with a modern infrastructure. The current Country's population is around 29 million and is growing annually at the rate of 2.8 percent. At present, the population residing in urban areas is 82 percent. As per Ministry of Municipal and Rural Affairs (MMRA) forecast, 88 percent of the Kingdom's population will be living in urban areas by 2025 , exerting severe social, economic and environmental consequences. The key urban problems witnessed in the major cities of the Kingdom of Saudi Arabia are:

- Uncontrolled low density sprawled urban expansion (fig. 1).

- Absence of adequate public urban transport system

- Poor supply of residential land and shortage of affordable housing units.
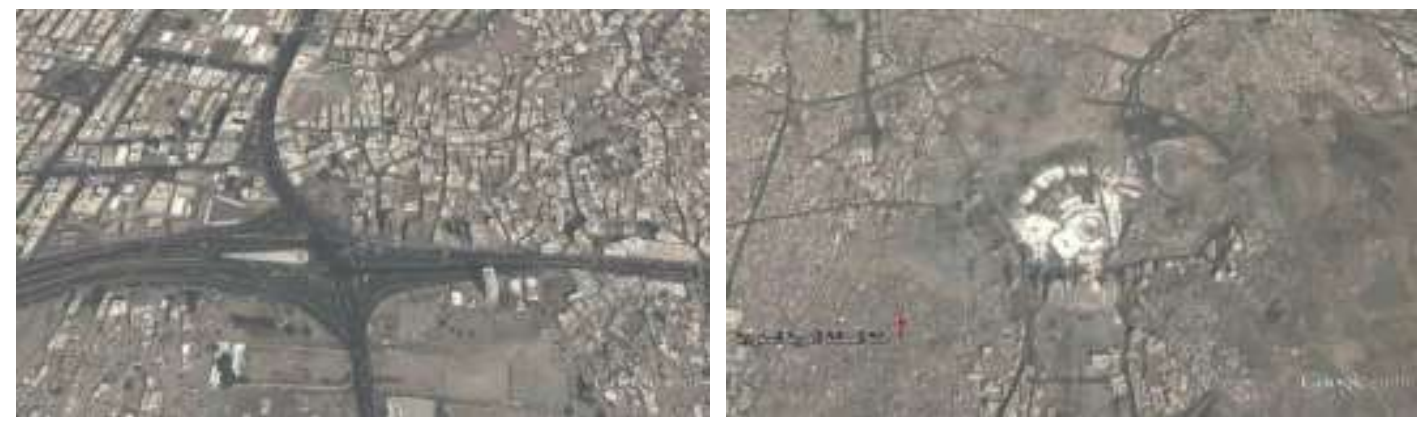

Fig. 1:- Unfortunately, the overall Arial view of the Holy City of Makkah, reveal the scarcity of all kinds of urban outdoor open spaces. No heretical green net of recreational areas, no adequate urban plazas, no residential gardens,

\footnotetext{
${ }^{3}$ Wang Jianguo, (1999), Modern urban design theory and method, Southeast University Press, Nanjing

${ }^{4}$ Wu Liangyong, 1999, Beijing Declaration, China Building Industry Press, Beijing

${ }^{5}$ Al-Hathloul, S. A. (1981). Tradition, continuity and change in the physical environment: the

Arab-Muslim city. PhD Thesis, Massachusetts Institute of Technology, USA
} 
nothing, just scattered areas, planted with grasses and unpleasant design. Which increases energy consumption, for cooling indoor areas, and cause "heat island effect", in which resulted in a severe hot climate.

Source: Google Earth

Despite robust growth of the Saudi economy, developments in the transport sector have not been forthcoming. The poor state of public transport infrastructure is a fall-out of years of neglect. Easy accessibility to private automobiles and low fuel prices have steadily increased automobile traffic levels leading to rise in congestion and accidents in urban areas. Traffic accidents have become a serious problem facing the country. During the period from 1971 to 1994, the numbers of traffic accidents, injuries, and fatalities have increased by 30 times, 6 times, and 7 times, respectively ${ }^{6}$ (Fig.2).
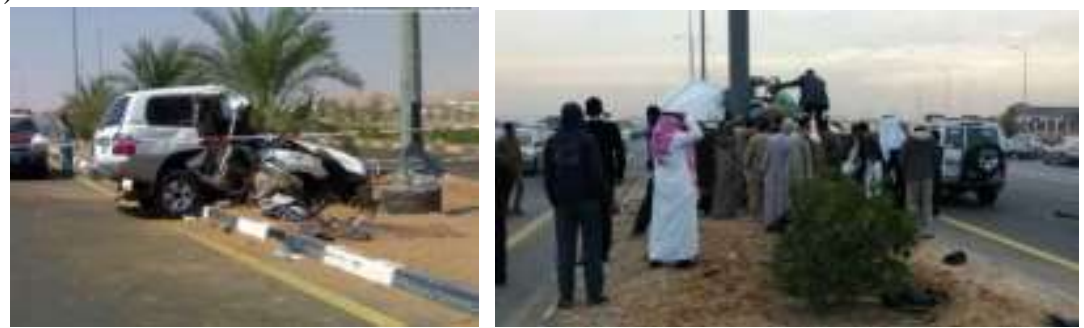

Fig. 2:- The inadequacy of planning and design of traffic streets, the lack of crash barriers and reckless driving caused a fatal traffic accidents, which resulted of 18000 annually rate death in Saudi Arabia. Source: http://hoshan.org/2012/01/car-accident-king-abdul-aziz-road-buraidah-saudi-arabia-january-7-2012/

It is the time now, to encourage environmental designer and decision makers, to think carefully to satisfy the needs of local society for a more adequate neighborhoods planning and design, with open space for civic opportunities, sidewalks and streets based on the grid system, an integrated use of mixed-residential, retail, and office space within walking distance from residential units, Creating and maintaining aesthetically appealing, functionally efficient and healthy environment (Fig.3). ${ }^{7}$
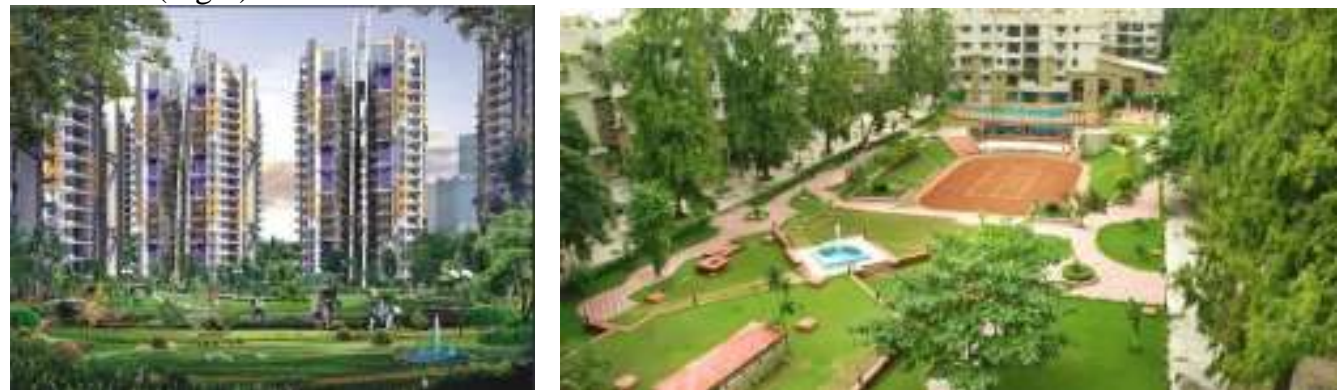

Fig. 3:- Creating and maintaining aesthetically appealing, functionally efficient and healthy environment Source: http://www.srijanrealty.com/

\section{Residential Environment:-}

Residential environment refers to the living places, the relevant living surrounding and the corresponding cognitive psychology in the scope of residential areas ${ }^{8}$. Residential area is the independent area which has a certain degree of population and land size for daily life. On the other side, the residential buildings, public buildings, green space, roads and other types of engineering facilities have a closed connection. The residential area is also surrounded by the city streets or natural boundaries. Due to the impact from many factors such as a reasonable radius of utility services, spacing of the city streets, and the administrative management system, the reasonable scale of residential

\footnotetext{
${ }^{6}$ Ali. S. Al-Ghamdi1( ND), ROAD ACCIDENTS IN SAUDI ARABIA: A COMPARATIVE AND

ANALYTICAL STUDY, Dept. of Civi. Eng., King Saud Univ., Riyadh, Saudi Arabia.

${ }^{7}$ Chadchan Jayprakash (2000), “An approach to explore and outline alternative sustainable urban development pattern for new towns and urban extensions in Saudi Arabia", College of Environmental Design King Fahd University of Petroleum and Minerals, Saudi Arabia .

${ }^{8}$ Al-Hathloul, S. A. (1981). Tradition, continuity and change in the physical environment: the Arab-Muslim city. PhD Thesis, Massachusetts Institute of Technology, USA
} 
area is generally $50,000 \sim 60,000$ population (not less than 30,000 people), 50 to 100 hectares of land around ${ }^{9}$. Nowadays, people have more demands not only for more space for simple daily needs but also for a higher quality of living such as leisure, entertainment and harmonious neighborhood relations. As an extension of the indoor environment, the outdoor environment of residential areas is the environment surrounding buildings. Residential outdoor environment is also the most basic space for people's daily activities as indoor environment. It is a biological environment centered about human beings and composed of the natural environment, artificial environment and social environment.

\section{Residential environment development:-}

At the present time, people have more demands not only for more space for simple daily needs but also for a higher quality of living such as leisure, entertainment and harmonious neighborhood relations. The overall design concept for a new residential environment development, should seek to provide contrast and interest balanced by unifying elements to provide coherence and identity. As well as greater variety in the spatial form of residential spaces and places, this will entail a greater diversity of dwelling form and type to help produce a lively street scene. For instance, terraced buildings may be used to enclose a space, while elsewhere a taller building may be used to create a landmark feature. Coherence can be created in the detailed design of the different dwelling types by following the best local traditions of form, materials and detailing. Developers will be required to provide details of the boundary treatment of buildings as this can significantly affect the overall quality and character of new residential environment (Figure4).

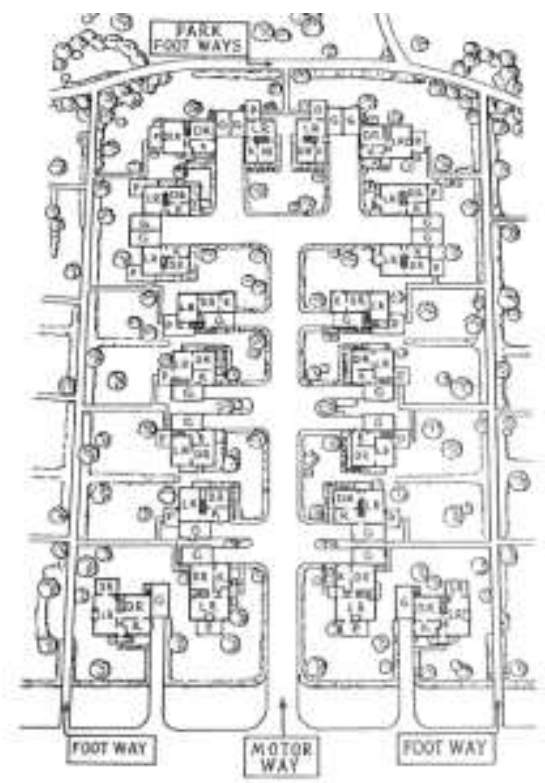

Fig. 4:- Plan for the conversion of the central area into a facility serving, the elderly, young children, and teens. Source: Oscar Newman, (1996), Institute for Community Design Analysis, U.S. Department of Housing and Urban Development Office of Policy Development and Research

Regard should always be given to ways of integrating pleasant, attractive and landscaped areas of residential spaces and place, including children's play spaces, as an essential element of any new residential development to meet the needs generated by that development. Residential open space not only has recreational and social value, but is also considered vital to the overall design quality of the development. It can help promote biodiversity and contributes to the creation of an attractive, sustainable and varied residential environment, helping to 'green' an area, soften any environmental impact and foster a sense of community (Fig 5).

All open space areas should be suitably located, proportioned and planted. Narrow or peripheral tracts which are difficult to manage will not be acceptable. Well-designed space around buildings can add greatly to the

\footnotetext{
${ }^{9}$ Zhao Min, Zhao Wei,( 2003), Community development planning-theory and practice, China Building Industry
} Press, Beijing 
attractiveness of a development, especially where the principles of defensible space to be regarded as an important programs to restructure the physical layout of communities to allow residents to control the areas around their homes. This includes the streets and grounds outside their buildings and the entrances and passageways within the residential environment development, to help people preserve those areas in which they can realize their commonly held values and lifestyles. Developers should therefore make adequate provision for open space in the form of gardens, parks, urban plazas, patios, balconies or terraces, depending on the characteristics of the development proposed and the surrounding context (Fig.5 \&6).
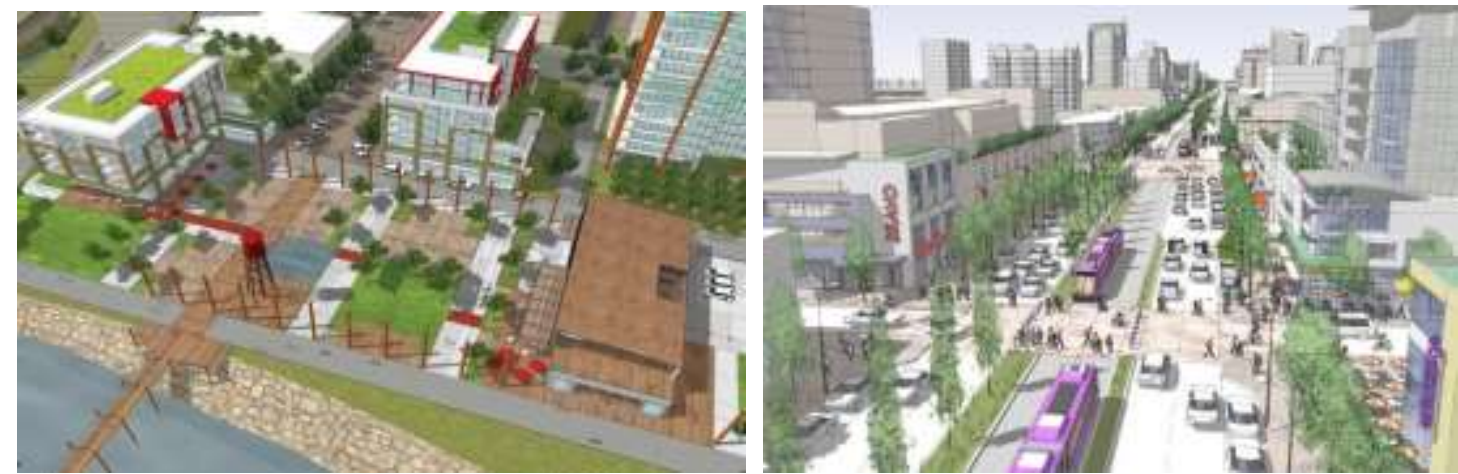

Fig. 5:- Regard should always be given to ways of integrating pleasant, attractive and landscaped areas of residential spaces and place, including children's play spaces, as an essential element of any new residential development to Source: http://www.dialogdesign.ca/ meet the needs generated by that development.
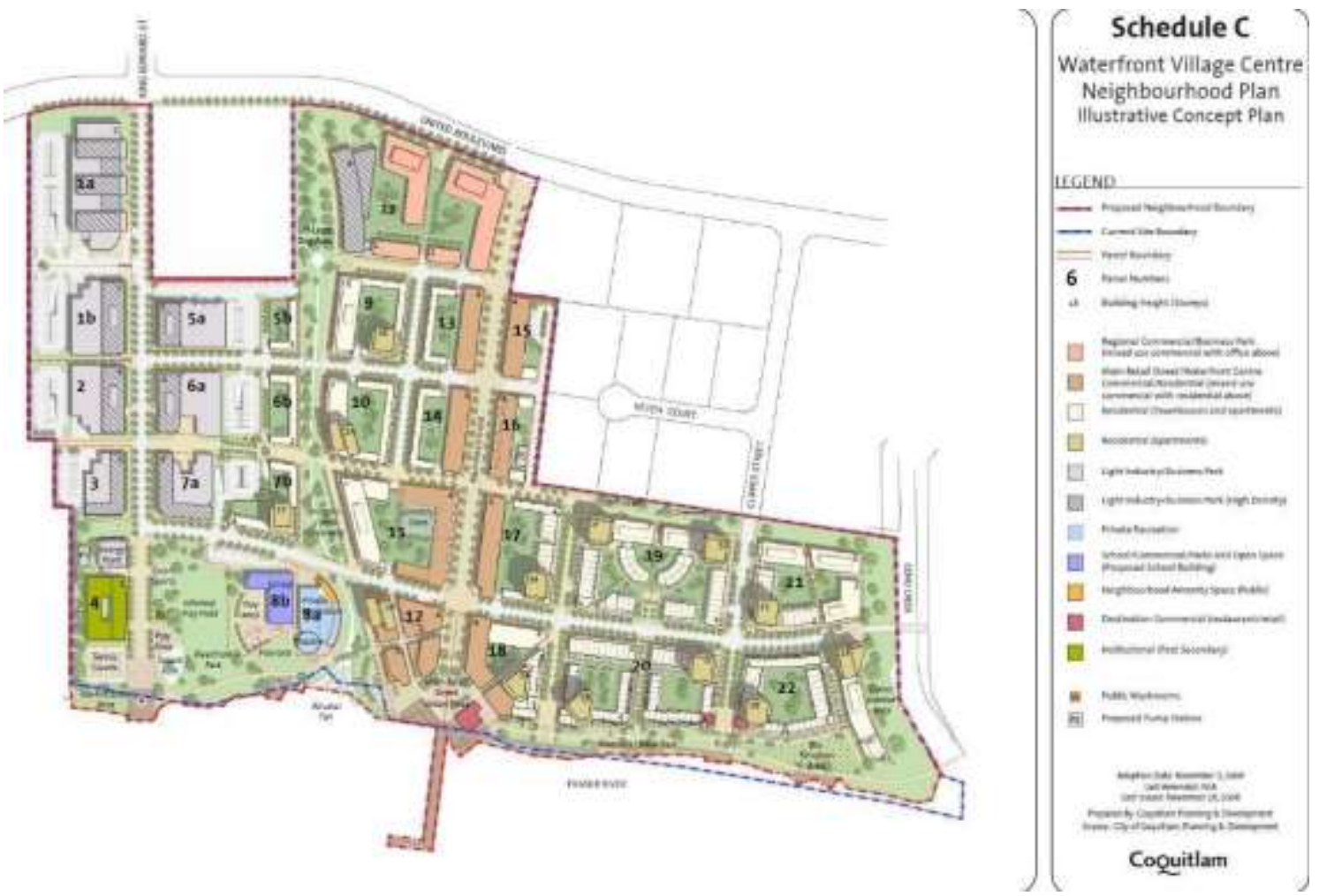

Fig. 6:- provision for open space in the form of gardens, parks, urban plazas, patios, balconies or terraces, depending on the characteristics of the development proposed and the surrounding context

Source: http://www.dialogdesign.ca/

In short, as an extension of the indoor environment, the outdoor environment of residential areas is the environment surrounding buildings. Residential outdoor environment is also the most basic space for people's daily activities as 
indoor environment. It is a biological environment centered about human beings and composed of the natural environment, artificial environment and social environment (Fig. 7).
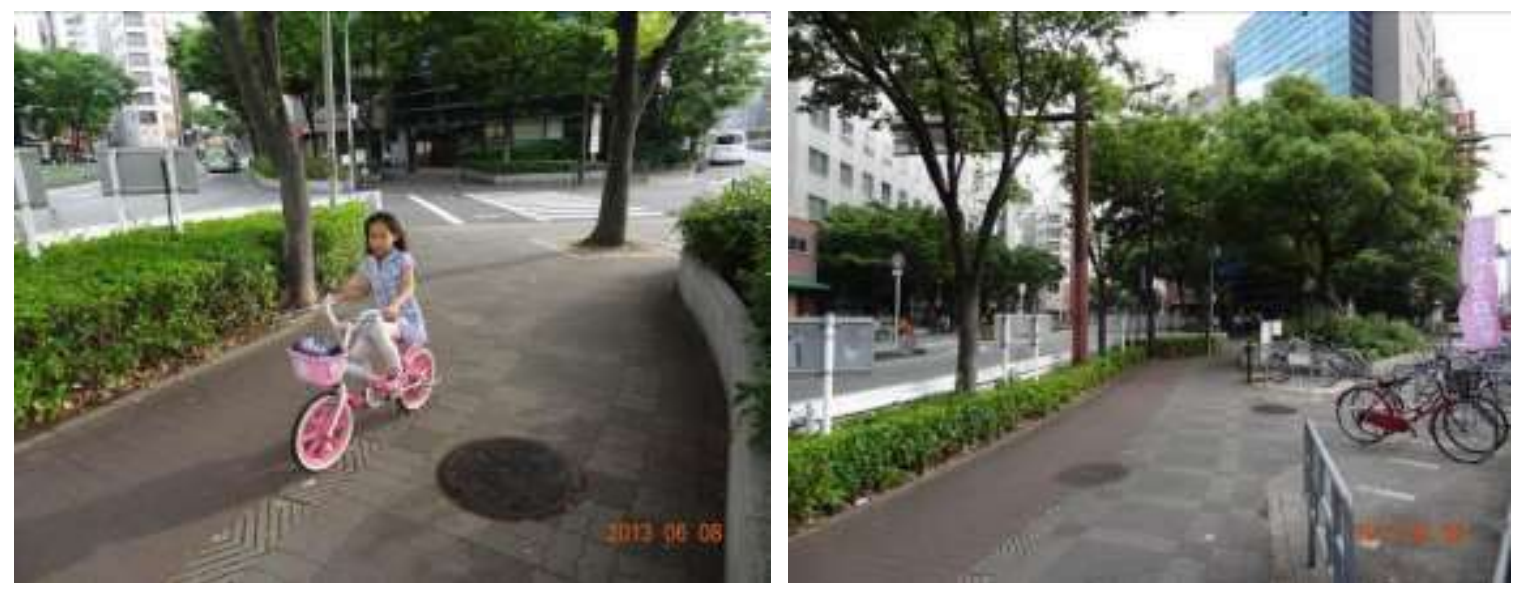

Fig. 7:- Developers should therefore make adequate provision for open space in the form of gardens, parks, urban plazas, patios, balconies or terraces, depending on the characteristics of the development proposed and the surrounding context.

Source: author (2013). A residential garden, Osaka, Japan

\section{Landscape Design of Residential Area:-}

Residential landscape is not only providing residents a vision, but also, at the same time functioning well for residents. Therefore, the combination of form and function is the point of residential areas landscape design. The constituent elements of residential areas landscape can be divided into two types. One is the composition of substances, namely: people, architecture, green, water, roads, infrastructure, and other entities. Another one is the spiritual and cultural components, namely: the history of environmental context and cultural characteristics.

Residential landscape is the inseparable unity of the two types and the spiritual connotation was demonstrated through the material elements, which is possessed of culture as well (Fig 4).

\section{Residential Landscape Space and Place Classification:-}

According to different classified criteria, residential landscape Space and Place could be divided into different types, according to the type of people outdoor activities. Jan Gehl (2001) ${ }^{10}$ divided outdoor activities into three types in the book of Life between buildings: necessary activity, spontaneous activity and social activity. The requirements of each type for the physical environment are completely different. According to these three types of activities, residential landscape Space and Place could be divided into three categories (Fig.8).

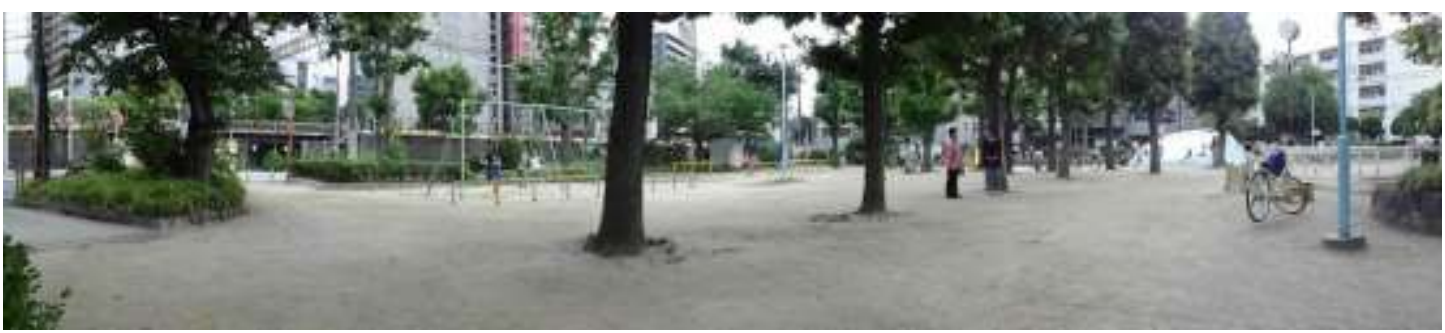

\footnotetext{
${ }^{10}$ Jan Gehl, (2001, Life between Buildings, The Danish Architectural Press, Copenhagen
} 

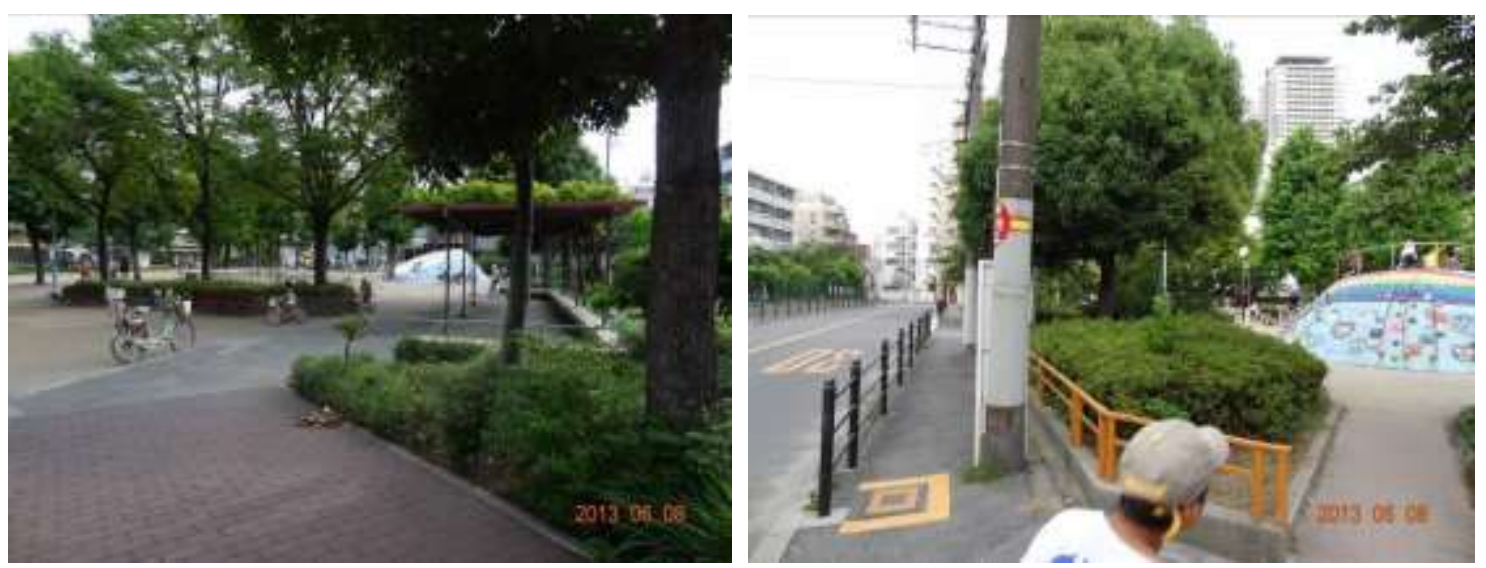

Fig. 8:- Residential landscape is not only providing residents a vision, but also, at the same time functioning well for residents.

Source: author (2013) Osaka, Japan

\section{Necessary Activity Space:-}

The necessary activity includes activities which are involuntary such as work, studying, shopping, waiting, etc. In other words, people are more or less taking part in the activities being as part of daily life. As most of those activities are related to walk, the road becomes an essential element regarding to the necessary activities in space. Because these activities are the ones which would be carried out by people, this kind of landscape space mainly provides the basic functions for citizen activities. The necessary activity space is the basis of other types of space (Fig. 9).
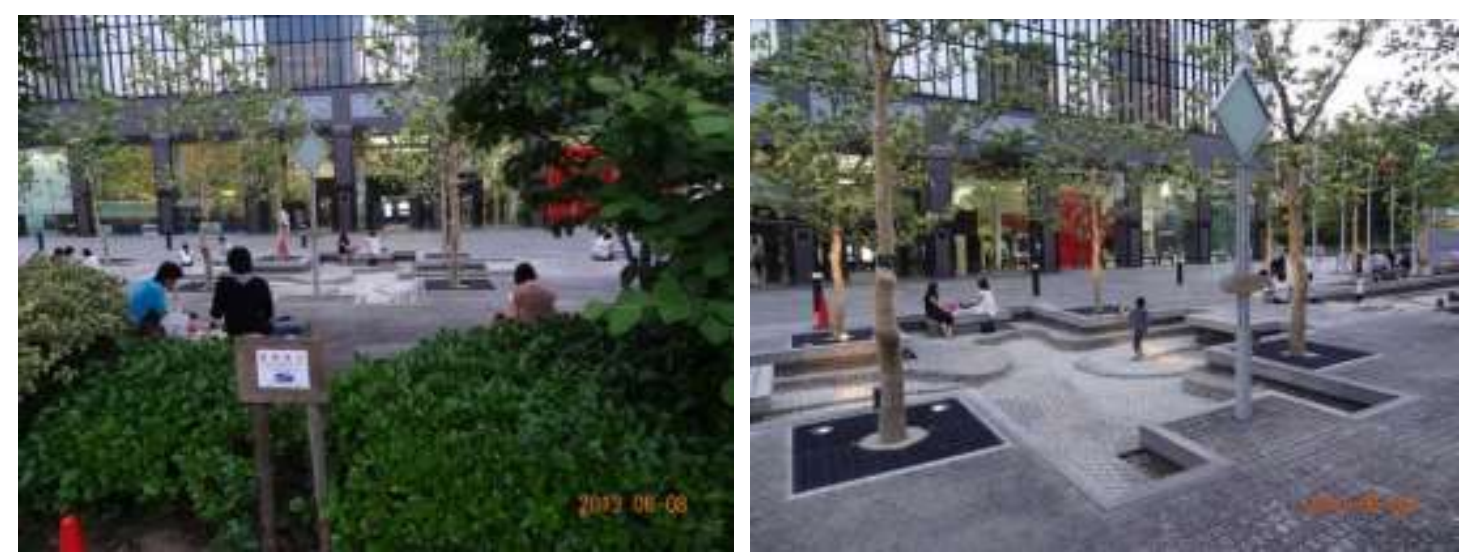

Fig. 9:- The necessary activity includes activities which are involuntary such as work, studying, shopping, waiting, etc. In other words, people are more or less taking part in the activities being as part of daily life Source: author (2013) Osaka, Japan

\section{Spontaneous Activity Space:-}

Spontaneous activity space is put forward from spontaneous activities and means generated activities when people want to participate, and when the time and place is possible. Such activities include walking, playing with dog and a breath of fresh air, morning exercises and watching interesting things and so on. These activities will happen when external conditions are appropriate, just as the weather and the environment is attracting. Therefore, the activities need a high requirement for the environment and in another words, it will need an even higher requirement for the spontaneous activities. Such space environment is not only for function but also requiring more design. For example, the gravel paving patterns or stepping stone road should be more interesting than the cement road. The landscapes have a variety of objects, such as sculptures, fountains, etc. which is elements of spontaneous activity space and could rich the landscape as well (Fig. 10). 

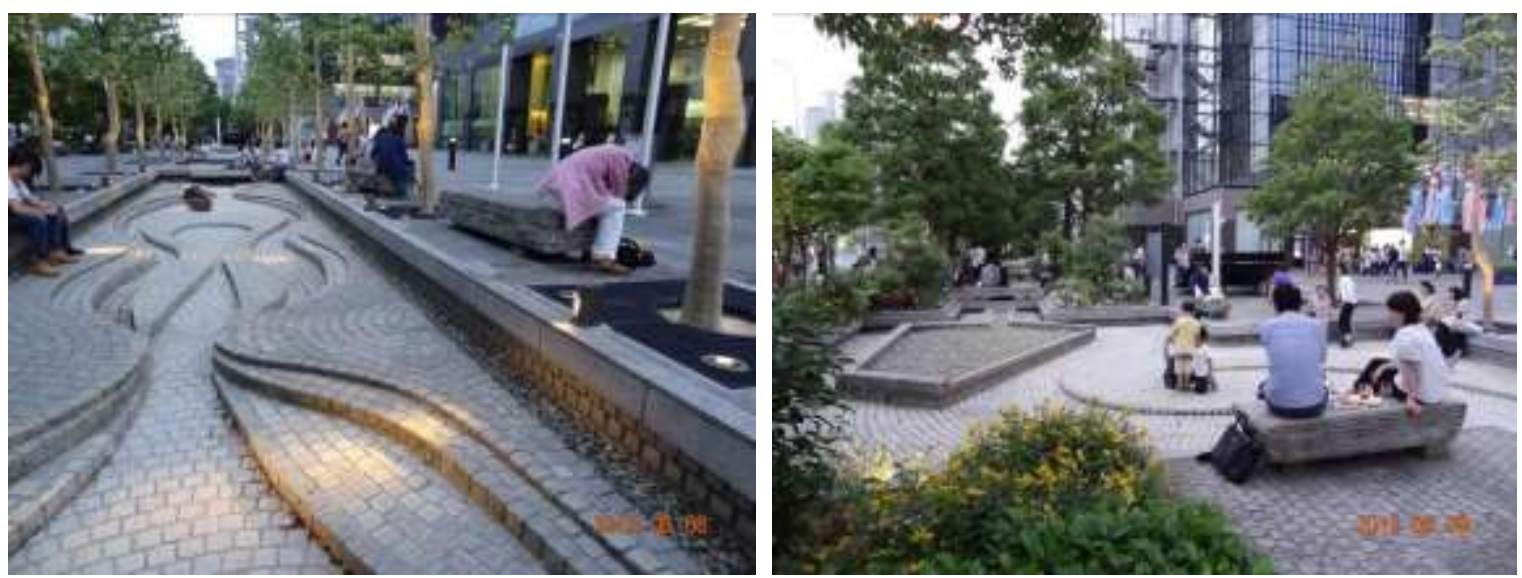

Fig. 10:- Spontaneous activity space is put forward from spontaneous activities and means generated activities when people want to participate, and when the time and place is possible. Such activities include walking, playing with dog and a breath of fresh air, morning exercises and watching interesting things and so on.

Source: author (2013) Osaka, Japan

\section{Sociality Events Spaces:-}

Societal activity refers to the various activities in public space where people would like to participate. It includes greeting, talking, children's games, small-scale leisure activities and so on. Such activities could be generated in the various occasions and could be regard as an extension of spontaneous activities. The social activity space has a wide range and society activities could be happened in most of the public space. Of course, the quality of the space will still affect the activities. If the space has a comfortable and pleasant environment, people would like to hang around, relax, and stay in the same space. Also, it will naturally bring more various social activities and increase the communication for the residents and create active atmosphere in residential area (Fig. 11).
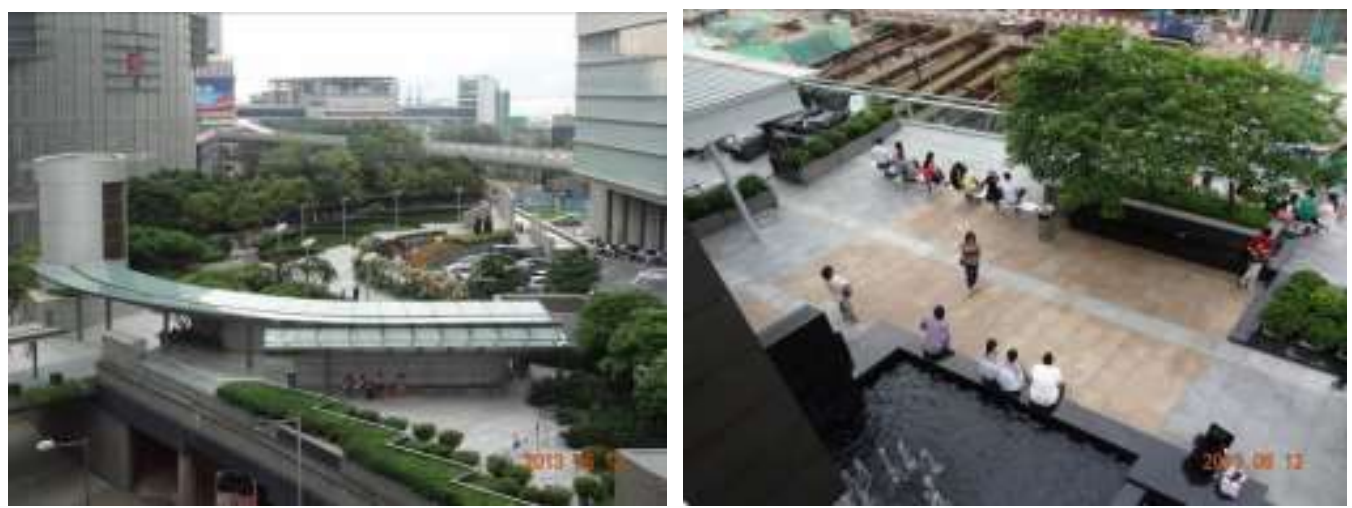

Fig. 11:- Societal activity refers to the various activities in public space where people would like to participate. It includes greeting, talking, children's games, small-scale leisure activities and so on.

Source: (2013) Hong Kong.

The Evaluating Principles of Landscape Quality of Residential Spaces and places:-

Residential landscape Spaces and places are important part of the city environment as. Their quality will have directly effect on the city image, even the whole society. The evaluation principals of landscape residential spaces and places might as following contents: Site Selection, Overall Planning and Landscape Function.

\section{Site Selection:-}

Generally environment around the area will have abundant effect on the quality of the residential landscape open space and place (fig. 12). Mostly, the density of people will be lower and people could have more activity space if the district is far away from the city. On the other hand, the quality of the living is not at high level. This situation could be evaluated by: 
- site area,

- building area,

- building density,

- plot ratio,

- greening rate,

- green space area per capita ,

- Water area per capita.

\section{Overall Planning:-}

For example, it is hot arid weather all-year around in City of Makkah, and the trees there are not so sufficient nor planted in proper location. In the researcher opinion, more plants can be planted in residential landscaping areas. There could appropriately increase the amount of green space, which could create a pleasant green environment and effectively improve micro-climate as well. The residential landscape design also has diverse requirements, for this feature, the following elements should be gained more attention: Local Climate, topography, Resource distribution, and surrounding of environmental characteristics (Fig.12 \& 13).

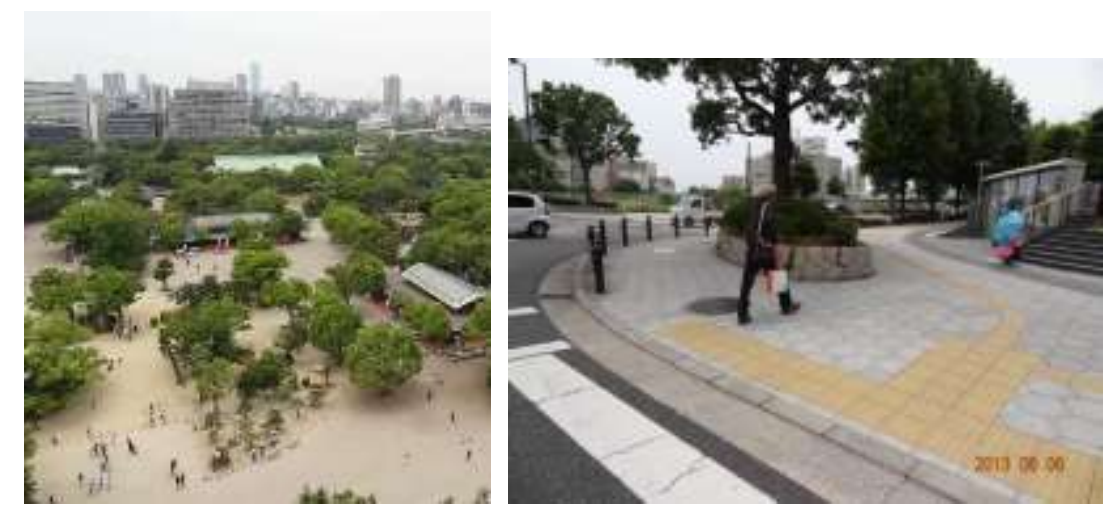

Fig. 12:- The neighborhood park is intended to provide an outdoor living room for the neighborhood. Source: author (2013) Osaka, Japan
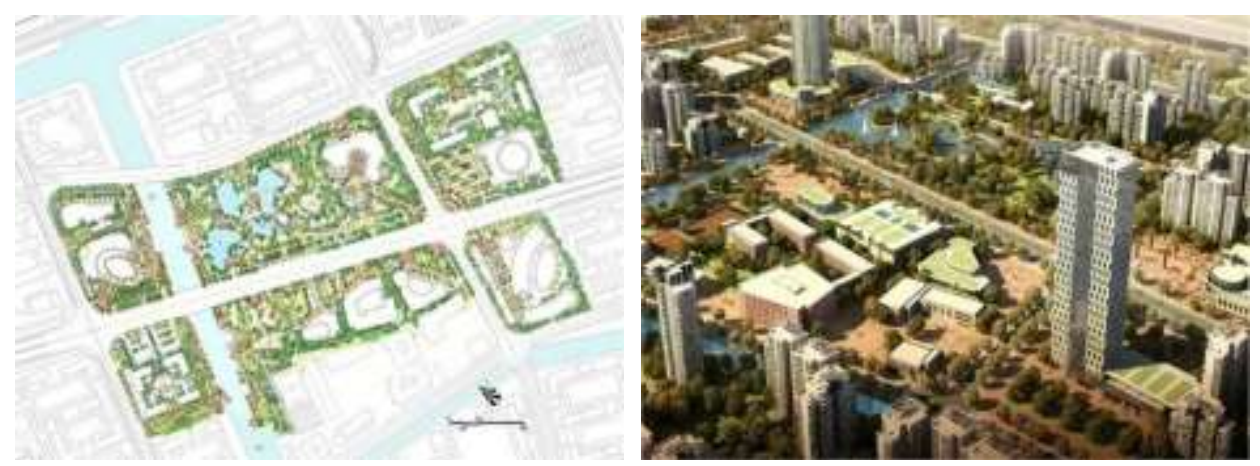

Fig. 13:- There could appropriately increase the amount of green space, which could create a pleasant green environment and effectively improve micro-climate as well, for example,Qizhong Maqiao Large-scale residential landscape design that has diverse requirements,

Source: http://www.thape.com/en/project_details.php?type=1\&project=134

\section{Landscape Function:-}

The outdoor environment of inhabitation is created by variety kinds of space, green, landscape pieces and service facilities. Residential landscape is the important space for people's daily life. Whatever the landscape is, it has to meet the different need of people's basic usage (Fig14). It is not suitable for landscape without any function. Furthermore, the residents are composed in residential areas by different social classes, ages and genders. The common and different requirements for different people on the environment should be appreciated. As a good residential area, the environment and facilities should meet the needs of various residents within residential areas. Some practical facilities would be focused and observed as follows: 
- Amenities for rest (Site furniture suchlike chairs, benches.)

- Accommodations for leisure (Monument, fountains.)

- Services for children entertainment.

- Services for transport (Street furniture, for instance Street lamps, signpost.)

- Abilities for disabled person (ramps, safe areas.)

- Facility for sanitation (Trash bins, shelters, grading and drainage).
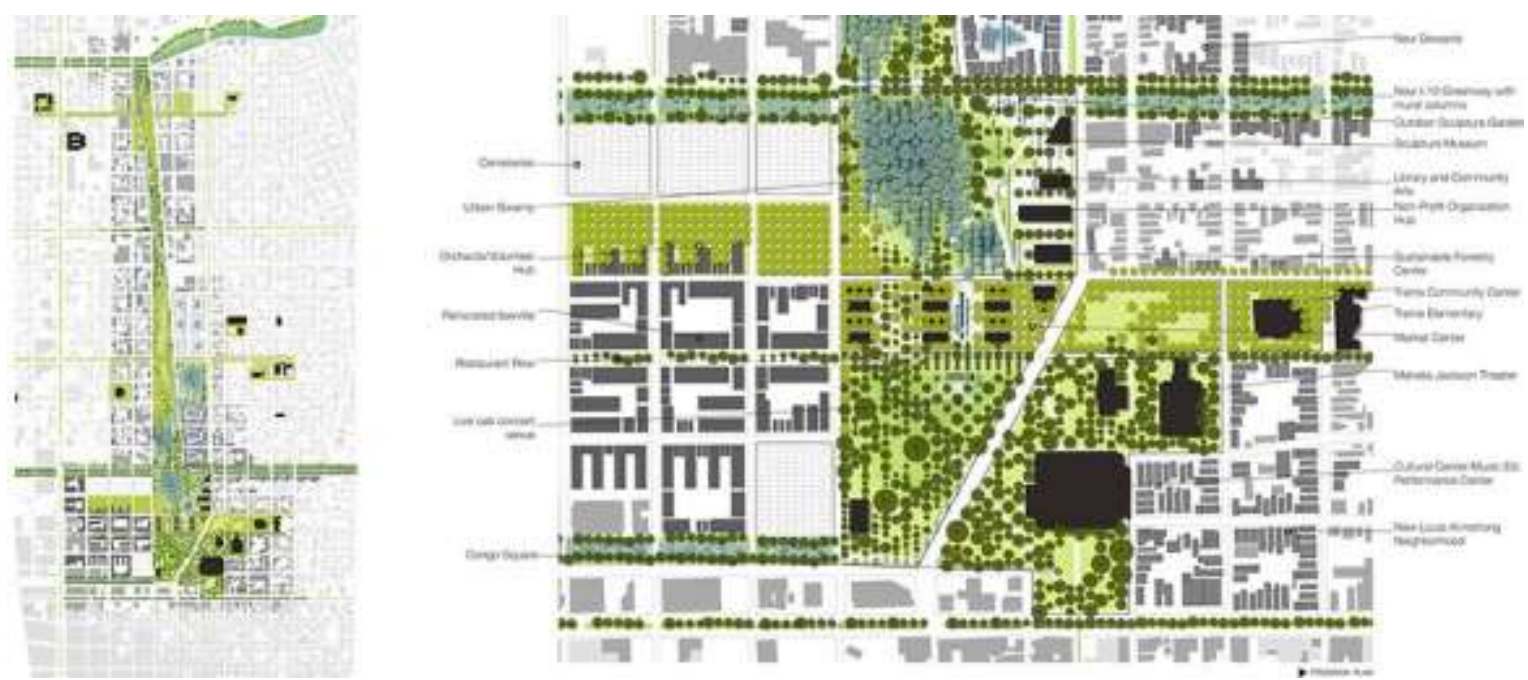

Fig. 14:- The outdoor environment of inhabitation is created by variety kinds of space, green, landscape pieces and service facilities. Residential landscape is the important space for people's daily life, that support a denser residential/commercial organization.

Source: http://scenariojournal.com/article/urban-regeneration/

\section{Comfort as a basic requirement of the landscape design:-}

Public space is the main space in residential area, including roads, green spaces, and squares and so on. Therefore, whether there is a comfortable shared space will affect the quality of the environment in the residential areas. Meanwhile, the comfort is also a basic requirement of the landscape design. In this context, it is preferable to establish a comfortable road system, because the roads seem like skeleton and the reasonable design of road system has directly effects on the residents traveling and security. Adding to that, the appropriate scale of space could enhance the using efficiency and improve the comfort as well (Fig.15).
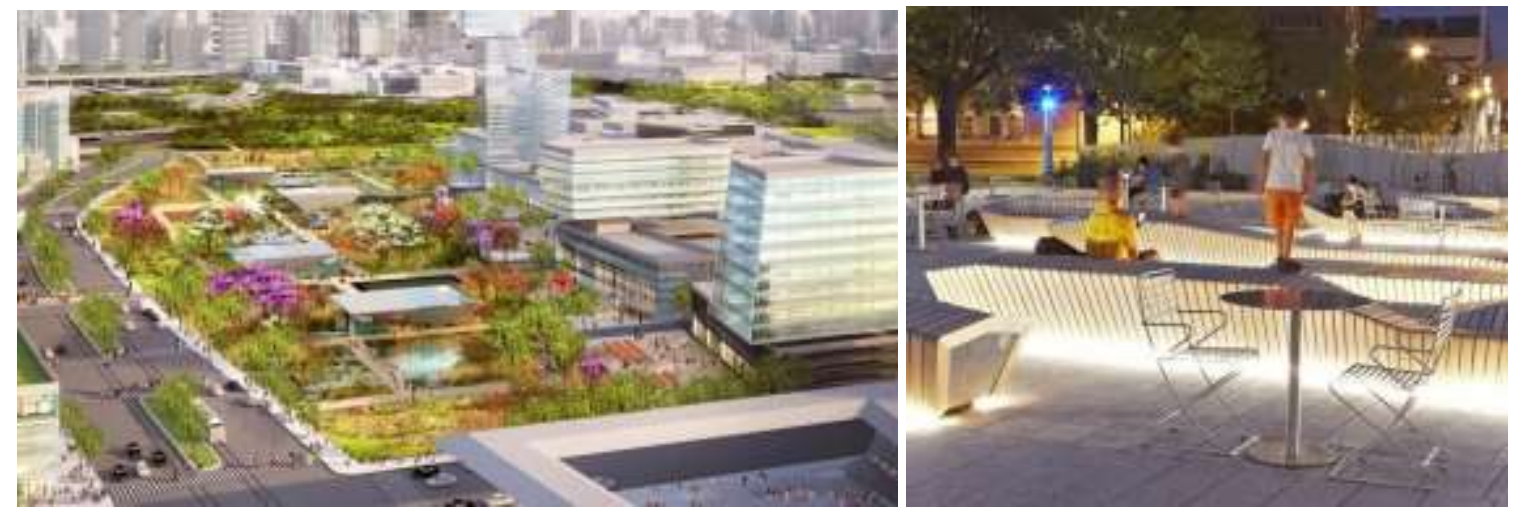

Fig. 15:- Public space is the main space in residential area, including roads, green spaces, and squares and so on. Therefore, whether there is a comfortable shared space will affect the quality of the environment in the residential

Source: http://www.stoss.net/projects/27/ areas. 


\section{A multi - level green Residential Spaces and places: Privacy Issue:-}

Green is not only the most extensive and frequently used part of living environment, but also the closest natural environment and having the greatest influence on residents in urban landscape. A multi - level green Residential Spaces and places might be the better ecological and optical effects than the large areas. If a residential district has some a multi - level green Residential Spaces and places, its landscape quality will be better.

Adding to that, the importance of a suitable private space, the same as shared public space, private space is also an indispensable element in landscape design. The residential area having a suitable private space or not is one of the appraisal criterion (Fig.16). It includes:

- The number of private space

- The scale of private space

- The extent of its privacy

- Surrounding environment

- Reliability and security
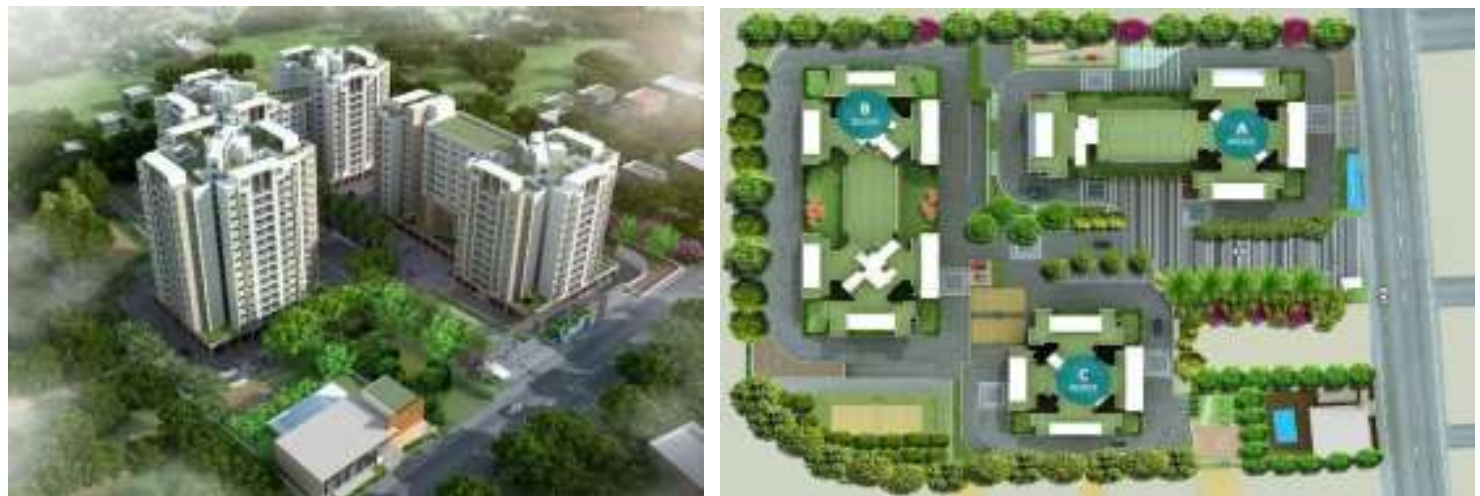

Fig. 16:- Green is not only the most extensive and frequently used part of living environment, but also the closest natural environment and having the greatest influence on residents in urban landscape.

Source: http://avantebyvasathi.blogspot.com/

\section{Design streets of residential spaces and places:-}

A Street has important public realm functions beyond the movement of traffic. These functions include placemaking, providing access to buildings, parking, and the location of public utilities and public lighting. While it is essential to provide for movement along the street, designers also need to consider the appropriate balance between these different functions, and not treat one in isolation. ${ }^{11}$ Streets do not just serve a movement function, and their design should include consideration of appropriate opportunities for resting and enjoyment (Fig17). The following design principles should guidance the layout and design of streets in residential spaces and places:

1- Connectivity and permeability: Convenient access needs to be provided between and community and commercial facilities and to places of work within areas, and should be accessible for everyone as direct as possible.

2- Sustainability: Priority should be given to the needs of walking, cycling and public transport, and the need for car-borne trips should be minimized;

3- Safety: Streets, paths and cycle routes should provide for safe access by users of all ages and degrees of personal mobility;

4- Legibility: It should be easy for both residents and visitors to find their way around the area; and

5- Sense of place: Streets should contribute to the creation of attractive and lively mixed-use places.

\footnotetext{
${ }^{11}$ Traffic Control System Design for All Purpose Roads (2003), Printed and published by the Highways Agency.
} 

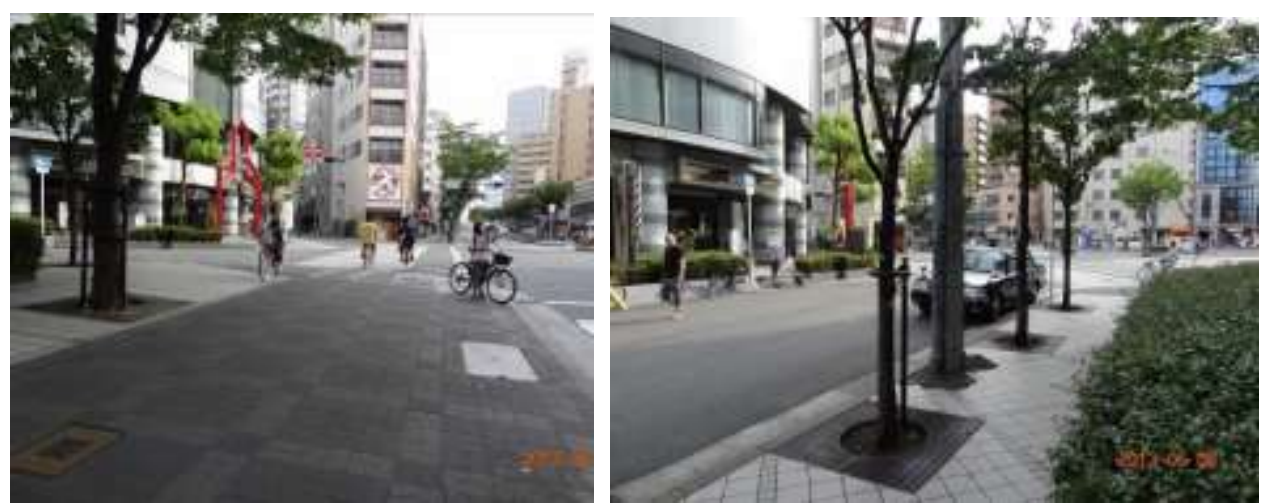

Fig. 17:- A Street has important public realm functions beyond the movement of traffic. These functions include place-making, providing access to buildings, parking, and the location of public utilities and public lighting.

Source: author (2013) Osaka, Japan

\section{The design of street layouts:-}

The design of street layouts must start by considering people movement rather than vehicle movement. This approach ensures greater consideration of pedestrians, cyclists and public transport users. In many instances, all users can comfortably share the same street network. When designing a street layout for a new residential area, designers should assess the need for, and specific roles of:

1) Links to the overall road network in the district or town, including bus services, based on an analysis of the need for such linkages;

2) Access to bus-based and rail-based public transport (where relevant);

3) Direct walking and cycling routes to local facilities such as shops, schools, public transport, and open spaces, together with lighting and landscaping of such routes;

4) Access for people with disabilities;

5) Maximum permeability for pedestrians and cyclists

6) Circulation routes for public service (buses, waste collection) and delivery vehicles within the area;

7) Residential streets with limited through motor traffic;

8) Consideration of provision for low design speeds (such as $30 \mathrm{kph}$ ) and facilities for pedestrians and cyclists;

9) The location and amount of parking for cars and cycles; and

10) The planting of appropriate street trees (bearing in mind the location of underground services).

Most residential streets - as witnessed by many existing streets in cities and towns - can successfully combine low to medium traffic movements with a pleasant residential setting, including on-street parking where street widths permit. The design should also allow for the delivery of goods and services (such as waste collection) to dwellings. Consideration should also be given to the needs of blind or presence of a footpath curb, visually impaired people who might normally rely on the pavements curb (Fig.18).
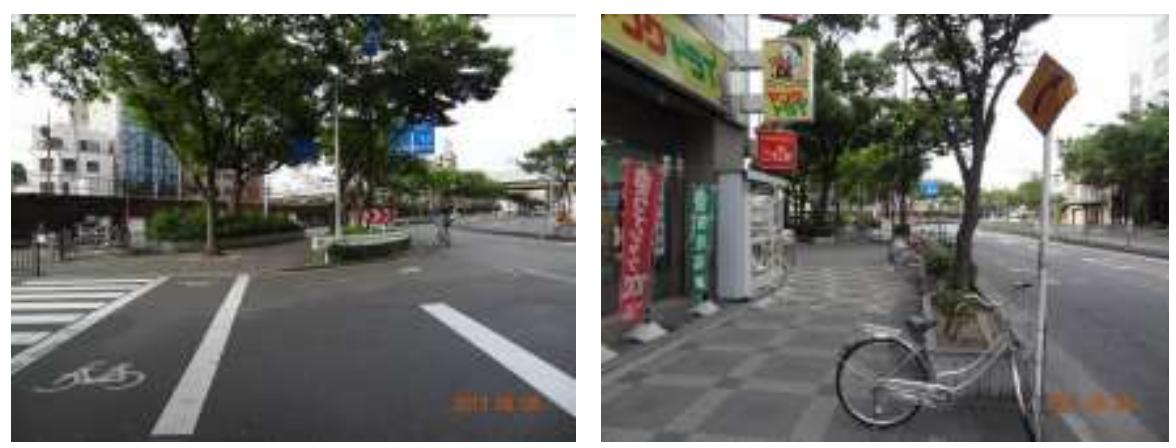

Fig. 18:- Most residential streets - as witnessed by many existing streets in cities and towns - can successfully combine low to medium traffic movements with a pleasant residential setting, including on-street parking where Source: author (2013) Osaka, Japan street widths permit. 


\section{Proposals for landscape residential Space and places development:-}

All proposals for residential development will be expected to conform to all of the following criteria (Fig.19):

1- The development respects the surrounding context and is appropriate to the character and topography of the site in terms of layout, scale, proportions, massing and appearance of buildings, structures and landscaped and hard surfaced areas;

2- Adequate provision is made for public and private open space and landscaped areas as an integral part of the development. Where appropriate, planted areas or discrete groups of plants will be required along site boundaries in order to soften the visual impact of the development and assist in its integration with the surrounding area;

3- Adequate provision is made for necessary local neighborhood facilities, to be provided by the developer as an integral part of the development;

4- A movement pattern is provided that supports walking and cycling, meets the needs of people whose mobility is impaired, respects existing public rights of way, provides adequate and convenient access to public transport and incorporates traffic calming measures;

5- Adequate and appropriate provision is made for parking;

6- The design of the development draws upon the best local traditions of form, materials and detailing;

7- The design and layout will not create conflict with adjacent land uses and there is no unacceptable adverse effect on existing or proposed properties in terms of overlooking, loss of light, overshadowing, noise or other disturbance; and the development is designed to deter crime and promote personal safety.

8- Promote social integration and provide accommodation for a diverse range of household types and age groups;

9- Any proposal for residential development which fails to produce an appropriate quality of design will not be permitted, even on land identified for residential use in a development plan.
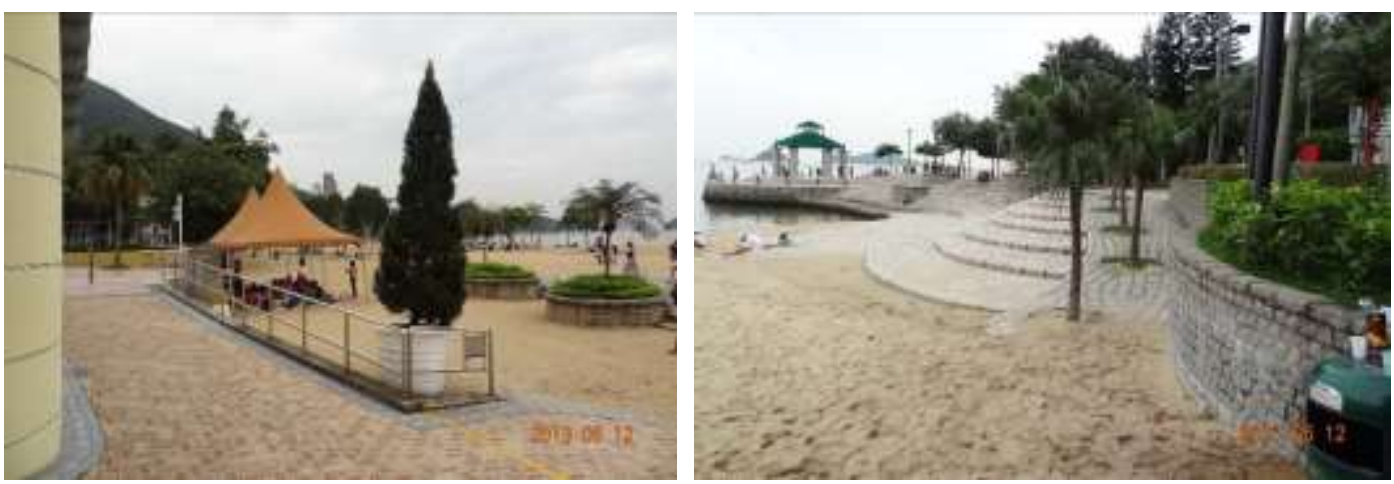

Fig. 19:- The development respects the surrounding context and is appropriate to the character and topography of the site in terms of layout, scale, proportions, massing and appearance of buildings, structures and landscaped and hard surfaced areas;

Source: author (2013) Osaka, Japan

In short, to enhance residential space and place in a city urban fabric, the following might be addressed:

1- Respect for landform, landscape and history of the site,

2- The creation of a distinctive sense of place,

3- Relationship to existing urban form,

4- The provision of open space, tree-lined avenues and local neighborhood facilities,

5- The provision made for walking, cycling and access to public transport,

6- The overall permeability and legibility of the layout (Fig.20). 

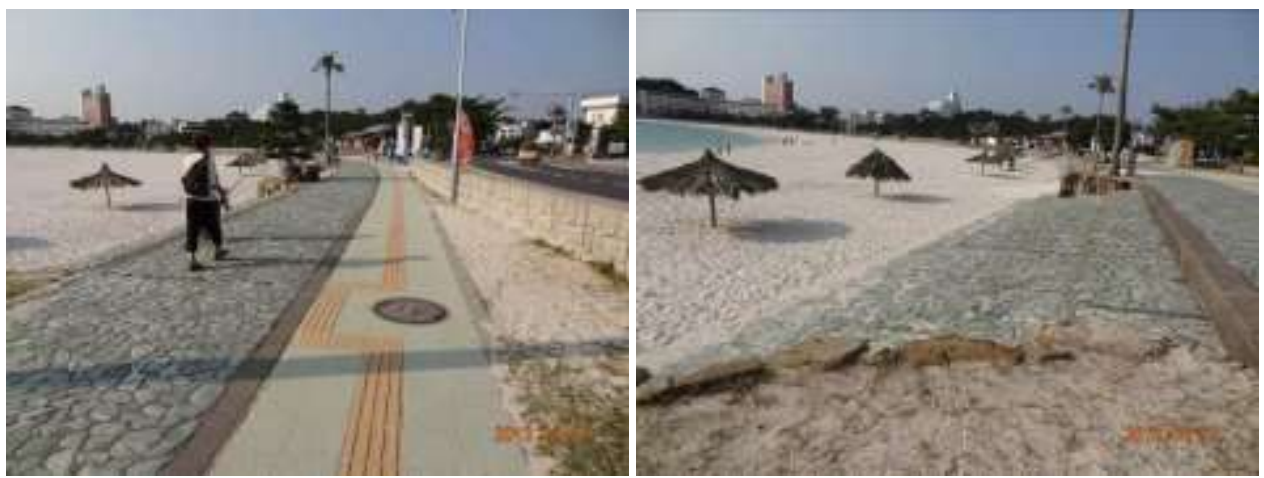

Fig. 20:- Respect for landform, creation of a distinctive sense of place, the overall permeability and legibility of the layout

Source: author (2013) Osaka, Japan

\section{Conclusion:-}

Landscape architects have been paid more attention to the development of landscape residential open spaces and places more valuable time. The environment of residential district has very close relationship with human's life. For the time being, it has vibrant effect on the city's improvement. Consequently, generating an enjoyable living setting becomes the communal goals. As the residential area is not only a place to live, but also a place to have activities for residents; and the quality of the residential landscape; also has strong effect on people's life, environmental designer , particularly landscape architects, ought to emphasis on the features to meet people's desires ,including both physical and spiritual.

Residential areas, in some Saudi city urban fabrics, were designed planned inadequate.

The design methods and principles for landscape were summarized to provide useful information and hopefully, to have some help in landscape design in future.

1. The issue of inadequate in planning and design, for residential landscape. First of all, the reasonable utilization and development landscape design based on the local situation in the residential area should be the guideline philosophy in the design.

2. The issues of emphasis only on the landscape styles, but lack of functions in the design of residential area. The first consideration in residential area design is the basic function of the areas to meet different people's needs at most, such as quite space for elder people, families, bachelors, entertainment place for children, and especially the facilities for disabled person, which needs to be specially designed. Based on the functions, more detailed designs could be added to enrich the landscape, which are not only decorations, but also could bring more interests to people. The layout and style of the design then should be considered after this.

3 . The issues of energy-consuming and pollution in residential area in every step of residential construction. First of all, a sustainable perspective should be added in the planning of residential area, in which the sustainable energy and material should be used. Eco-friendly and energy-saving material for construction should be first considered, such as solar energy and wind power. This is not only saving energy resources, but also having good impact on environment. In the scenery design in terms of energy efficacy and sustainable landscape, the design should match the local natural conditions. For example, the water landscape would be the first choice in the region with rich water resource by using recycling water system. However, large amount of using desalination water products to save nonrenewable fuel.

In conclusion, landscape being an important part in residential area has been caught much more attention as nice landscape could provide convenience, entertainment and 'high quality' life. However, the design of residential construction is still ongoing and in progress along with the development of the society. Hopefully, the result of this research might provide some useful information for Saudi residential spaces and places construction.

\section{Further Reading:-}

1. Bai Dehan, 1991, Residential area planning and environmental design, Chinese Architecture Industry Press, Beijing

2. Beevers R., 1988, The Garden City Utopia: A Critical Biography of Ebenezer Howard, London: Macmillan 
3. Bollerey F. and Hartmann K., 1980, A Patriarchal utopia: the garden city and housing reform in Germany at the turn of century, in Sutcliffe, A. (ed.), pp. 151-154

4. Chen Jinsong, 2004, Community, Big way, Machinery, China Industry Press, Beijing

5. Clarence Perry, 1923, New York Regional Plan

6. David Rudlin, Nicholas Falk, 1999, Building the 21st Century Home, The sustainable urban neighborhood, Architectural Press, England, pp.53-56, 101-106

7. Donald Olsen, 1986, The City as a Work of Art: London, Pairs, Vienna, Yale University Press

8. Douglas Kelbaugh, 1997, Common Place: toward Neighborhood and regional Design, University of Washington Press, Washington.

9. Freidrich E., 1844, The Condition of the working class in England, reprinted 1952

10. Hall P., 1988, Cities of Tomorrow: An Intellectual History of Urban Planning and Design in the Twentieth Century. Oxford: Blackwell

11. Howard E., 1898, To-morrow: A Peaceful Path to Real Reform. London: Swan Sonnenschein

\section{Electronic Sources}

1. Environment, Encyclopedia, http://baike.baidu.com/view/49629.htm

2. Lele Zhao, 2009, Community, Encyclopedia

http://baike.baidu.com/view/49629.htm

3. Letchworth

http://en.wikipedia.org/wiki/Letchworth_Garden_City

4. The Crystal City homepage

http://crystalcity.vanke.com/mb.htm

5. The Fifth Garden homepage

http://shenzhen.vanke.com/products/city/fifthgarden/

6. The Western Harbor

http://www.managenergy.net/products/R295.htm 